\title{
Catabolic Pathways for Streptokinase, Plasmin, and Streptokinase Activator Complex in Mice
}

\author{
IN VIVO REACTION OF PLASMINOGEN ACTIVATOR WITH \\ $\alpha_{2}$-MACROGLOBULIN
}

\author{
Steven L. Gonias, Monica Einarsson, and Salvatore V. Pizzo, Departments of \\ Pathology and Biochemistry, Duke University Medical Center, Durham, \\ North Carolina 27710; Kabi Vitrum AB, Research Department, S-112 87 \\ Stockholm, Sweden
}

A B S T RACT The catabolic pathways of streptokinase, plasmin, and activator complex prepared with human plasminogen were studied in mice. ${ }^{125} \mathrm{I}$-streptokinase clearance occurred in the liver and was $50 \%$ complete in $15 \mathrm{~min}$. Incubation with mouse plasma had no effect on the streptokinase clearance rate. Complexes of plasmin and $\alpha_{2}$-plasmin inhibitor were eliminated from the plasma by a specific and saturable pathway. Competition experiments demonstrated that this pathway is responsible for the clearance of injected plasmin. Streptokinase-plasminogen activator complex formed with either ${ }^{125} \mathrm{I}$-plasminogen or ${ }^{125} \mathrm{I}$-streptokinase cleared in the liver at a significantly faster rate than either of the uncomplexed proteins $(50 \%$ clearance in $<3 \mathrm{~min}$ ). Streptokinase incubated with human plasma also demonstrated this accelerated clearance. $\quad p$-Nitrophenyl- $\boldsymbol{p}^{\prime}$-guanidinobenzoate- $\mathrm{HCl}$ or pancreatic trypsin inhibitor-treated complex cleared slowly compared with untreated complex independent of which protein was radiolabeled. Significant competition for clearance was demonstrated between $\alpha_{2}$ macroglobulin-trypsin and activator complex only when the plasmin(ogen) was the radiolabeled moiety. Large molar excesses of $\alpha_{2}$-plasmin inhibitor-plasmin failed to retard the clearance of activator complex. Hepatic binding of streptokinase-plasmin, in liver perfusion experiments, was dependent upon prior incubation with plasma (8-10\% uptake compared to a background of $\sim 2.5 \%$ ). Substitution of human $\alpha_{2}$-mac-

This work was supported by a grant from the National Heart, Lung and Blood Institute (HL24066). Mr. Gonias is a Predoctoral Fellow, Medical Scientist Training Program (GM-07171).

Received for publication 7 December 1981 and in revised form 2 March 1982. roglobulin for plasma also resulted in binding when the incubation was performed for $10 \mathrm{~min}$ at $37^{\circ} \mathrm{C}$ (7.5\%). Electrophoresis experiments confirmed the transfer of $0.8 \mathrm{~mol}$ plasmin $/ \mathrm{mol} \alpha_{2}$-macroglobulin when activator complex was incubated at $37^{\circ} \mathrm{C}$ with $\alpha_{2}$-macroglobulin for $40 \mathrm{~min}$. Streptokinase transfer from activator complex to $\alpha_{2}$-macroglobulin was negligible. The in vivo clearance of activator complex is proposed to involve active attack of the complex on the $\alpha_{2}$-macroglobulin "bait region," resulting in facilitated plasmin transfer. Dissociated streptokinase is rapidly bound and cleared by sites in the liver.

\section{INTRODUCTION}

Streptokinase is a bacterial protein that possesses no inherent enzymatic activity, but forms a noncovalent one-to-one stoichiometric complex with human plasminogen or plasmin $(1,2)$. This complex functions as a plasminogen activator. The association reaction is extremely rapid and the two proteins do not readily dissociate under neutral, nondenaturing conditions $(3,4)$.

The therapeutic potential of streptokinase as a thrombolytic agent was first demonstrated with extravascular clots by Tillett and Sherry (5). In a subsequent study streptokinase was found to be equally effective in the lysis of intravascular clots (6). Patients diagnosed in the early stages of myocardial infarction were considered as candidates for streptokinase therapy by Fletcher et al. (7). Since then, numerous studies have been published concerning streptokinase therapy in deep vein thrombosis and myocardial infarction.

Little is known about the metabolism of streptokinase. Plasma elimination studies conducted in dogs and organ distribution studies in mice have yielded some- 
what inconsistent results $(8-10)$. None of these studies have addressed the issue of species variability in the reactivity of plasminogen with streptokinase. Limited association of intravenously administered streptokinase with plasminogen to form activator complex occurs in the circulation of dogs, and none in the circulation of mice (11). In human patients, however, the major fraction of an injected streptokinase dose would be expected to immediately form activator complex $(3,11)$. How the activator complex is eliminated from the circulation is unclear especially in consideration of its large size $(>120,000)$ and numerous studies that detail its lack of reactivity with the major plasma protease inhibitors $(3,12,13)$.

In this investigation, the plasma elimination pathways of streptokinase, plasmin, and activator complex are studied with both in vitro experiments and in vivo experiments in mice. Use of the mouse as a model for the catabolism of these proteins in man offers the following advantages. (a) Mouse plasminogen is completely nonreactive with streptokinase (11). This finding, which is confirmed here, permits a comparison of the catabolism of free streptokinase to streptokinase activator complex formed in vitro with human plasminogen before injection. (b) Human and mouse protease inhibitors including $\alpha_{2}$-macroglobulin $\left(\alpha_{2} M\right)$, $\alpha_{1}$-proteinase inhibitor, and antithrombin III have been shown to bind proteases and clear on receptor systems in mouse without distinction attributable to crossing species lines (14-16). ${ }^{1}$ Evidence is presented here suggesting that protease inhibitors are critical in the elimination of both free plasmin and streptokinaseplasmin(ogen) complex. $\alpha_{2}$-Plasmin inhibitor $\left(\alpha_{2} \mathrm{PI}\right)^{2}$ is shown to be the major regulatory protein for injected plasmin in the dose range studied. This finding is in good agreement with studies that consider $\alpha_{2} \mathrm{PI}$ the primary inhibitor of circulating plasmin (17-19). Alternatively, when plasmin is injected as part of a preformed complex with streptokinase, $\alpha_{2} M$ reacts with the protease and functions in the clearance of the complex.

\section{METHODS}

Reagents. $\quad P$-nitrophenyl- $\boldsymbol{p}^{\prime}$-guanidinobenzoate- $\mathrm{HCl}$ (PNPGB) was purchased from Sigma Chemical Co., St. Louis, MO. ${ }^{125}$ Iodine and lactoperoxidase coupled to Sepharose were obtained from New England Nuclear, Boston, MA and P-L Biochemicals, Milwaukee, WI, respectively. The plasmin substrate H-D-valyl-L-leucyl-L-lysine- $p$-ni-

\footnotetext{
${ }^{1}$ Gonias, S. L., A. Balber, W. J. Hubbard, and S. V. Pizzo. Manuscript in preparation.

${ }^{2}$ Abbreviations used in this paper: $\alpha_{2} \mathrm{M}, \alpha_{2}$-macroglobulin; $\alpha_{2}$ PI, $\alpha_{2}$-plasmin inhibitor; PNPGB, $p$-nitrophenyl- $p^{\prime}$ guanidinobenzoate- $\mathrm{HCl}$; $\mathrm{PTI}$, pancreatic trypsin inhibitor.
}

troanilide $2 \mathrm{HCl}(\mathrm{S}-2251)$ is a Kabi Company product. Electrophoresis reagents were purchased from Bio-Rad Laboratories, Richmond, CA. All other reagents were of the best commercial grade available.

Proteins. Plasminogen was purified from human plasma by affinity chromatography on lysine-Sepharose as described by Deutsch and Mertz (20) and modified by Brockway and Castellino (21) to include gradient elution. Urokinase was purchased from Abbot Diagnostics, North Chicago, IL. Highly purified streptokinase was prepared from Kabikinase (Kabi Company) as previously described (22). Plasminogen was activated by incubation at a 500 -fold molar excess with streptokinase for $\mathbf{4 0} \mathrm{min}$ in sodium phosphate-buffered saline pH 7.4. Activation was also accomplished after incubation of $10 \mu \mathrm{g}$ of plasminogen with 6 Ploug units of urokinase for $2 \mathrm{~h}$ at $37^{\circ} \mathrm{C}$. Plasminogen preparations that were activated by either method were electrophoresed on $\mathrm{NaDODSO}_{4}$ gels after reduction with dithiothreitol. Gels were scanned using a Gelman ACD-15 automatic integrating densitometer (Gelman Sciences, Inc., Ann Arbor, MI). Before reaction with streptokinase or urokinase, plasminogen electrophoresed as a single band (Glu-plasminogen) (23). Activation was assessed as the decrease in protein electrophoresing as plasminogen accompanied by an increase in protein electrophoresing in new bands attributable to the heavy and light chains of plasmin (23). Only preparations that were $>95 \%$ activated, as determined by densitometry, were used in the clearance, autopsy, and liver perfusion experiments described below.

Trypsin was purchased from Worthington Biochemicals, Freehold, NJ. This preparation was $70 \%$ active as determined by active site titration (24). Bovine serum albumin was obtained from Sigma and macroalbumin was prepared as described (25). Pancreatic trypsin inhibitor (PTI) was purchased under the trade name Trasylol from Mobay Chemical Co., Pittsburgh, PA. Human $\alpha_{2} M$ was purified as previously described (15). $\alpha_{2}$ PI was a generous gift of Dr. Peter Harpel. This preparation yielded a single band following $\mathrm{NaDODSO}_{4}$ gel electrophoresis. When incubated for 2 min with an equimolar concentration of plasmin, $\alpha_{2} P I$ inhibited $>99 \%$ of the hydrolysis of a plasmin specific substrate, S-2251 compared with an equivalent aliquot of plasmin not incubated with inhibitor.

Protein concentrations. The concentration of protein in purified preparations was calculated using the following extinction coefficients and molecular weight determinations: streptokinase, $A_{1 \mathrm{~cm}}^{1 \%}=7.5,50,200 \mathrm{~mol}$ wt (22); plasminogen, $A_{1 \mathrm{~cm}}^{1 x^{2}}=16.8,92,000 \mathrm{~mol}$ wt $(26) ; \alpha_{2} \mathrm{M}, A_{1 \mathrm{~cm}}^{1 \times}=8.93,718,000$ mol wt (27); $\alpha_{2} \mathrm{PI}, \mathrm{A}_{1 \mathrm{~cm}}^{1 \%}=7.03,67,000 \mathrm{~mol} \mathrm{wt} \mathrm{(28)}$.

Whole blood and plasma preparations. Whole blood for liver perfusion and clearance studies was obtained from mice by retroorbital puncture. Sodium citrate was added to these samples to inhibit coagulation (final concentration $0.38 \%$ ). Plasminogen-free plasma was prepared by incubating either mouse or human plasma with an equal volume of lysineSepharose for $60 \mathrm{~min}$ on an orbital rotator. The lysine-Sepharose was then pelleted by centrifugation in an Eppendorf microcentrifuge and discarded. The supernatant was combined with a second equal volume of lysine-Sepharose and incubated for $90 \mathrm{~min}$. Centrifugation was again performed and the supernatant retained for experiments. Blood and plasma samples from mice were used within $3 \mathrm{~h}$ of bleeding.

Protein radiolabeling. Proteins were radiolabeled with ${ }^{125}$ Iodine using the solid state lactoperoxidase method (29). Radioactivity was measured with a Scientific Products AW14-120 Gamma Counter (Scientific Products, Inc., Div. American Hospital Supply Corp., McGaw Park, IL). 
Polyacrylamide gel electrophoresis. Nondenaturing electrophoresis of both radiolabeled and nonradiolabeled proteins was conducted on slabs using the tris-borate buffer system described by Nelles et al. (30). Gels containing radiolabeled proteins were sliced into sections $0.4 \mathrm{~cm}$ long in the direction of migration after staining. The radioactivity present in each section was determined in a gamma counter. Radiolabeled protein content in electrophoretic bands was calculated using previously determined protein specific activity measurements.

$\mathrm{NaDODSO}_{4}$ gel electrophoresis was performed on 5 and 7.5\% ammediol-buffered slabs as described by Wyckoff et al. (31). Samples containing proteolytic activity were made $0.8 \mathrm{mM}$ in PNPGB before exposure to denaturing conditions. Denaturation proceeded for $40 \mathrm{~min}$ at $37^{\circ} \mathrm{C}$ in $1 \%$ SDS containing $10 \mathrm{mg} / \mathrm{ml}$ dithiothreitol unless otherwise specified.

Plasma elimination studies. Radiolabeled ligands alone or in the presence of unlabeled proteins and/or plasma were injected into the lateral tail veins of CD-1 female mice. Blood samples of $25 \mu \mathrm{l}$ were repetitively drawn from the retroorbital venous plexus, and radioactivity in these samples was measured in a gamma counter. Studies in which radiolabeled ligands were injected alone were performed with and without precipitation of sampled blood in $7.5 \%$ trichloroacetic acid, $0.4 \% \mathrm{KI}$ yielding results that were not significantly different. All single ligand studies were performed a minimum of four times. Competition experiments were performed at least in duplicate. This technique is described in detail elsewhere (15).

Liver perfusion. Anesthetized mice were incised at the midline, opening the abdominal cavity and transecting the sternum. The inferior vena cava was cannulated above the level of the renal veins and ligated above the diaphragm. The portal vein was severed and perfusion into the cannulated vena cava was initiated for 5 min at a rate of $\sim 1 \mathrm{ml} /$ min. The perfusion fluid consisted of $50 \mathrm{mM} \mathrm{NaHCO}, \mathrm{pH}$ 7.4 , and $60 \mathrm{mg} / \mathrm{ml}$, bovine serum albumin in Earle's Balanced Salt Solution. Perfusions that failed to completely blanch the liver were terminated. Radiolabeled samples contained within $1 \mathrm{ml}$ of perfusion fluid were injected into the cannulated vena cava at a rate slightly slower than $1 \mathrm{ml} /$ min. Perfusion with buffered Earle's Balanced Salt Solution containing bovine serum albumin was then reestablished for an additional $10 \mathrm{~min}$. The perfused livers were removed, washed, dried, and weighed before being measured for retained radioactivity. Perfusion studies were performed in triplicate. All results were obtained from livers that weighed within $5 \%$ of the mean weight.

Organ distribution studies. Animals were injected with radiolabeled ligands and then sacrificed by cervical dislocation. The major body organs including the kidneys, liver, lungs, heart, spleen, stomach, and intestines were recovered. These organs were soaked in perfusion buffer, dried, and measured in a gamma counter for retained radioactivity. These studies were performed in triplicate, and the results were averaged.

\section{RESULTS}

Clearance of purified streptokinase and plasmin. The clearance of radiolabeled uncomplexed streptokinase deviated only slightly from apparent first order kinetics (Fig. 1). Approximately 15 min were required for $50 \%$ of the injected radioactivity to clear from the circulation. Non-TCA precipitable counts represented

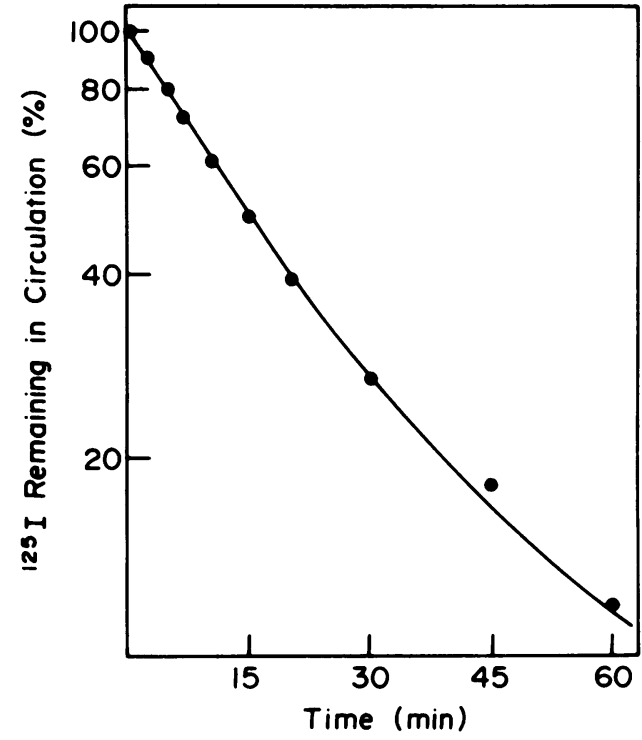

Figure 1 The plasma elimination of $0.3 \mathrm{nmol}$ of streptokinase. The percent of the injected radiolabel remaining in the circulation was calculated relative to an initial time point drawn $\sim 5-10 \mathrm{~s}$ after injection.

$<2.5 \%$ of the initial injection during the entire study. Addition of an 80-fold molar excess of unlabeled streptokinase to a sample containing $0.2 \mathrm{nmol}$ of radiolabeled ligand failed to slow the measured clearance rate. Competition was also not observed when $4 \mathrm{mg}$ of macroalbumin were included in the injection with the radiolabeled streptokinase. The absence of change in the clearance of streptokinase in these two studies suggests that reaction with circulating antibodies to streptokinase contributes minimally to the elimination of the isolated protein from the plasma.

The reaction of circulating plasmin with plasma protease inhibitors is well documented $(17-19,32)$. Thrombin has been shown to bind to high affinity sites on cells without first complexing to protease inhibitors (33); this possibility was explored for plasmin. When injected into the circulation of mice, human plasminogen is cleared very slowly (Fig. 2). The clearances of plasmin preparations activated with either streptokinase or urokinase are comparable and more rapid than plasminogen (50\% elimination in 16 and $18 \mathrm{~min}$, respectively). After reaction for $5 \mathrm{~min}$ with the active site alkylating agent PNPGB, plasmin, which can no longer react with protease inhibitors, is eliminated from the circulation at a rate approximating that of plasminogen. This is in sharp contrast to the results of the thrombin study in which both the active and inactive proteases behaved similarly (33). It therefore seems likely that the accelerated clearance demonstrated by plasmin, relative to plasminogen, results from reaction with protease inhibitors. 


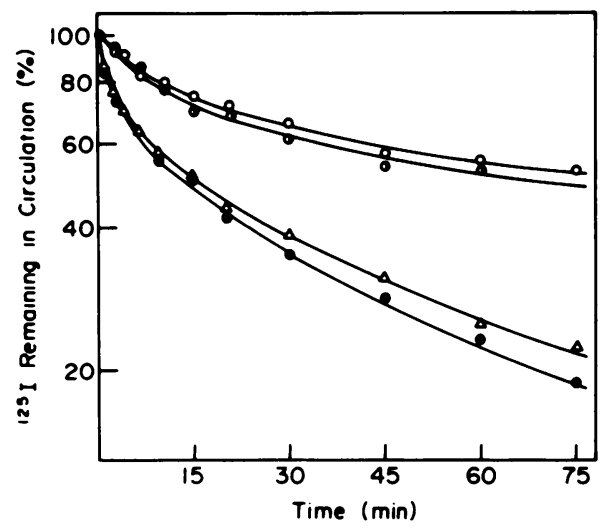

FIGURE 2 The activity requirement in the clearance of uncomplexed ${ }^{125} \mathrm{I}$-plasmin. Purified plasminogen was injected unmodified (O). Plasmin was cleared after activation with streptokinase $(\Theta)$ and urokinase $(\Delta)$ as described in Methods. Plasmin was active site alkylated with PNPGB $(100 \mu \mathrm{M})$ for $5 \mathrm{~min}(\mathrm{O})$. In each study $30 \mathrm{pmol}$ of plasmin(ogen) were injected in a final volume of $400 \mu \mathrm{l}$.

$\alpha_{2} \mathrm{PI}$ is the primary inhibitor of circulating plasmin; however, under certain conditions $\alpha_{2} \mathrm{M}$ may complex plasmin as well (32). The complex formed between $\alpha_{2} \mathrm{PI}$ and plasmin is extremely stable at neutral $\mathrm{pH}$ (34). Reactions between $\alpha_{2} M$ and proteases are irreversible (35). In the following studies plasmin complexes were formed in vitro with these two protease inhibitors and injected either alone or in the presence of competing ligand.

When incubated with an equimolar concentration of $\alpha_{2} \mathrm{PI}$, radiolabeled plasmin was $>99 \%$ inactivated as measured by its ability to hydrolyze the substrate $\mathrm{S}-2251$. The clearance of $6 \mathrm{pmol}$ of $\alpha_{2} \mathrm{PI}{ }^{125}{ }^{12}$-plasmin complex occurred at only a slightly decreased rate compared with free plasmin (Fig. 3). Approximately $20 \mathrm{~min}$ were required for $50 \%$ of the radioligand to be removed from the circulation. The same radiolabeled preparation was then injected in the presence of a large molar excess of unlabeled $\alpha_{2}$ PI-plasmin complex. Greater than $50 \%$ of the injected radioligand consistently remained in the circulation at $75 \mathrm{~min}$ suggesting that clearance of $\alpha_{2}$ PI-plasmin involves a specific and saturable pathway. A second competition experiment was performed in which $\alpha_{2} \mathrm{M}$-trypsin complex was the cold competing ligand present in a large molar excess. $\alpha_{2} \mathrm{M}$-protease complexes are removed from the circulation by a well studied receptor in the reticuloendothelial system $(15,36,37)$. A 700 -fold molar excess of $\alpha_{2} \mathrm{M}$-trypsin failed to retard the clearance of $\alpha_{2}$ PI-plasmin complex indicating that $\alpha_{2} \mathrm{PI}$ plasmin is eliminated from the circulation by a pathway distinct from that which recognizes $\alpha_{2} \mathrm{M}$-protease.

Unlike $\alpha_{2} \mathrm{PI}, \alpha_{2} \mathrm{M}$ reacts and becomes saturated with plasmin in a progressive, relatively slow reaction (38).

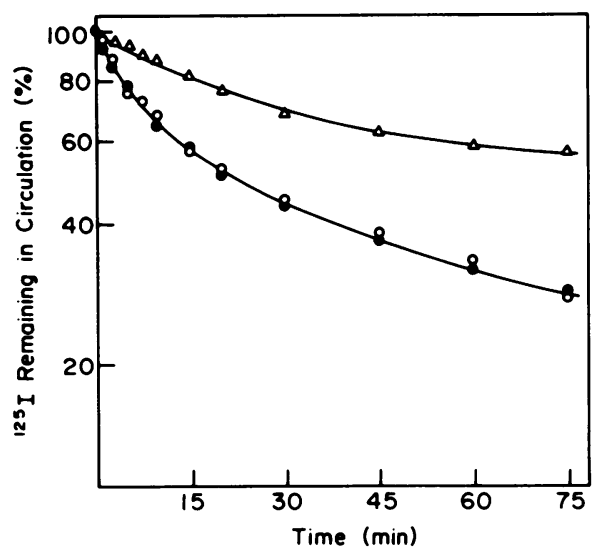

FigURE 3 The clearance of $\alpha_{2}$ PI-plasmin complex. $6 \mathrm{pmol}$ of ${ }^{125}$ I-plasmin were complexed with $\alpha_{2}$ PI (O). The same complex was also cleared in the presence of a 700 -fold molar excess of unlabeled $\alpha_{2}$ PI-plasmin $(\Delta)$ and a 600 -fold molar excess of unlabeled $\alpha_{2} \mathrm{M}$-trypsin (๑).

$\alpha_{2} \mathrm{M}$ was reacted with a twofold molar excess of ${ }^{125} \mathrm{I}$ plasmin for $40 \mathrm{~min}$. Unreacted protease was separated from complex on a Sephadex G-150 column $(22 \times 1.0$ $\mathrm{cm})$. Clearance of the complex from the circulation occurred rapidly (Fig. 4). Within $5 \mathrm{~min}, 50 \%$ of the injected $\alpha_{2} \mathrm{M}$-plasmin was removed from the plasma. Plasmin, prepared as an in vitro complex with $\alpha_{2} \mathrm{M}$, is therefore cleared significantly quicker than plasmin injected alone or in complex in $\alpha_{2}$ PI. Competition for clearance was observed when $\alpha_{2} \mathrm{M}$-plasmin was in-

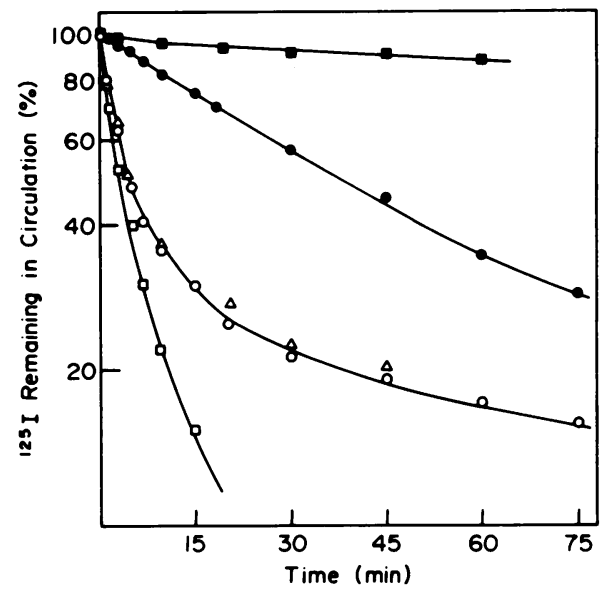

Figure 4 The clearance of $\alpha_{2} \mathrm{M}$-plasmin complex. $\alpha_{2} \mathrm{M}-{ }^{125} \mathrm{I}$ plasmin (30 pmol) $(O)$ and ${ }^{125} \mathrm{I}-\alpha_{2} \mathrm{M}$-plasmin $(\Delta)$ were prepared as described in the text. $\alpha_{2} \mathrm{M}^{125} \mathrm{I}$-plasmin was cleared in the presence of a 1,000-fold molar excess of $\alpha_{2} M$-trypsin complex $(\bullet)$. The clearance of native unreacted $\alpha_{2} M(\square)$, and $\alpha_{2} \mathrm{M}$-trypsin complex formed by reaction of radiolabeled $\alpha_{2} M$ with trypsin at a twofold molar excess for $10 \mathrm{~min}(\square)$ are included for comparison. 
jected in the presence of a 1,000-fold molar excess of unlabeled $\alpha_{2} \mathrm{M}$-trypsin. This result indicates that $\alpha_{2} \mathrm{M}$ plasmin binds to the same receptor system that recognizes $\alpha_{2} \mathrm{M}$-trypsin and $\alpha_{2} \mathrm{M}$-methylamine, but not unreacted $\alpha_{2} \mathrm{M}(15,36,37,39)$. $\alpha_{2} \mathrm{M}$-plasmin complex with radiolabeled $\alpha_{2} \mathrm{M}$ cleared equivalently to $\alpha_{2} \mathrm{M}$ plasmin with radiolabeled plasmin, suggesting that the complex clears as a unit. In either case, the clearance of $\alpha_{2} \mathrm{M}$-plasmin was marginally slower than $\alpha_{2} \mathrm{M}$ trypsin. A possible explanation for this is discussed below.

In a final set of plasmin clearance studies, uncomplexed ${ }^{125} I$-plasmin was injected in the presence of large molar excesses of unlabeled $\alpha_{2}$ PI-plasmin or $\alpha_{2} \mathrm{M}$ trypsin. The competing ligands were prepared so that the protease inhibitor present was saturated with protease and no longer reactive. The competing and radiolabeled ligands were injected sequentially with separate syringes to avoid reversible association of free radiolabeled ligand with competing complex, as has been described (40). Considerable competition for clearance was demonstrable when the competing ligand was $\alpha_{2}$ PI-plasmin (Fig. 5). $\alpha_{2}$ M-trypsin, however, failed to retard the clearance of the radiolabeled plas$\mathrm{min}$. These studies strongly suggest that the major fraction of the injected plasmin is binding to and clearing as a mouse $\alpha_{2}$ PI complex.

Clearance of streptokinase activator complex. Radiolabeled streptokinase ( $30 \mathrm{pmol})$ was incubated with an equimolar concentration of plasminogen for 5,20 , and $30 \mathrm{~min}$. Streptokinase-plasminogen complex is converted intramolecularly into streptokinase-plasmin during this time period (41). All three preparations

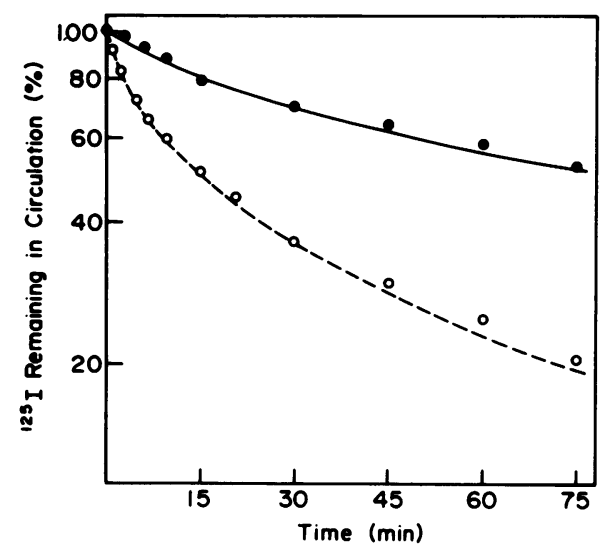

Figure 5 The role of $\alpha_{2} \mathrm{PI}$ and $\alpha_{2} \mathrm{M}$ in the neutralization and clearance of circulating plasmin. The clearance of active uncomplexed plasmin shown in Fig. 2 is duplicated here with a broken line. The equivalent preparation is injected in the presence of the unlabeled competing ligands: $\alpha_{2} \mathrm{M}$ trypsin at a 600-fold molar excess $(O)$ and $\alpha_{2}$ PI-plasmin at a 700-fold molar excess (0). were eliminated from the circulation extremely rapidly as compared to streptokinase, plasminogen, or plasmin alone (Fig. 6). Less than 3 min were required for $50 \%$ of the injected radiolabel to clear in each case. The time of incubation appeared to have no significant effect on the rate of clearance; however, potential differences are difficult to observe when the compared events occur over a short time interval. Plasminogen was activated with catalytic quantities of unlabeled streptokinase for $40 \mathrm{~min}$. The generated plasmin was then complexed with an equimolar concentration of ${ }^{125}$ I-streptokinase. The clearance of this preparation was indistinguishable from that of activator complex formed with plasminogen. Activator complex formed from ${ }^{125}$ I-plasminogen and unlabeled streptokinase cleared equivalently to complex formed with radiolabeled streptokinase. These data suggest that the complex clears as an intact unit. Alternatively, the possibility that the two proteins clear through separate accelerated pathways is also consistent with these data.

Plasminogen activator complexes were prepared in which either streptokinase or plasminogen was radiolabeled. These complexes were then incubated with PNPGB for $10 \mathrm{~min}$. The inactivated complexes cleared at a much slower rate than active complex (Fig. 6). Reaction of ${ }^{125} \mathrm{I}$-streptokinase-plasmin with excess PTI for $40 \mathrm{~min}$ resulted in an equivalent deceleration of clearance. Some variability was noted in the clearance in PNPGB-treated activator complex depending on

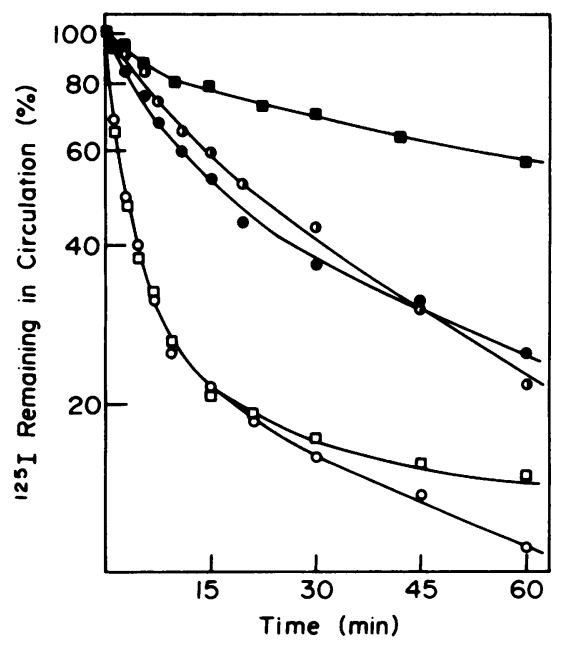

Figure 6 The clearance of plasminogen activator complexes formed from purified streptokinase and plasminogen. Activator complexes formed with ${ }^{125} \mathrm{I}$-streptokinase $(O)$ and with ${ }^{125}$ I-plasminogen (a) were studied without modification. Streptokinase- ${ }^{125}$ I-plasmin was inactivated with excess PNPGB as described in the text $(\square)$. The equivalent inactivation was performed with complex containing radiolabeled streptokinase (0). ${ }^{125} \mathrm{I}$-Streptokinase-plasmin was reacted with excess PTI for $40 \mathrm{~min}$ before injection (๑). 
which protein was radiolabeled. A possible explanation for this observation is discussed below. The clearance of inactivated complex in all of the above experiments was, nevertheless, slower than the clearances of either streptokinase or plasmin alone. Therefore, activity is critical for the retention of the greatly accelerated clearance rate demonstrated by plasminogen activator complex.

Clearance of proteins incubated with plasma. Radiolabeled streptokinase $(0.2 \mathrm{nmol})$ was incubated with $450 \mu \mathrm{l}$ of mouse plasma for $30 \mathrm{~min}$ at 23 and $37^{\circ} \mathrm{C}$. Plasminogen-depleted plasma was then substituted for untreated plasma and the same studies repeated. The clearances of these preparations were equivalent to each other and to the clearance of unreacted streptokinase shown in Fig. 1. These data support the previous finding that streptokinase does not form activator complex with plasminogen from the mouse (11). In addition, it is considered unlikely that any type of streptokinase-plasma protein interaction represents the rate limiting step in the clearance of the uncomplexed radioligand.

Human plasma was substituted for mouse plasma and the incubations described above were performed for $7 \mathrm{~min}$. This substitution accelerated the clearance of the ${ }^{125}$ I-streptokinase so that it was equivalent to that demonstrated by activator complex formed with purified plasminogen, suggesting that complex formation occurs readily in human plasma. Incubation of ${ }^{125}$ I-streptokinase with human plasminogen-depleted plasma resulted in clearances that were somewhat variable; however, always intermediate between the clearances of activator complex and uncomplexed streptokinase. It is possible that this variability reflects strong association between streptokinase and even ex- tremely small quantities of retained plasminogen in the modified plasma preparations.

Organ distribution studies. Radiolabeled streptokinase, plasmin, and activator complex were injected intravenously. Table I shows the organ distribution of radioactivity at the given times. Streptokinase initially concentrates in the liver. At later time points, there is an apparent transfer of radioactivity to the gut. This transfer has been observed before $(9,10)$. Comparable results were obtained when activator complex and plasmin were studied. Again, radioactivity was initially sequestered in the liver. At later time points radioligand accumulated in the gut especially with activator complex containing ${ }^{125} \mathrm{I}$-streptokinase. The possibility that the biliary system is involved in this process has been suggested for uncomplexed streptokinase (10). Immunoglobulin A-secretory component is transported rapidly and intact from the liver to the small intestine via the biliary system (42). The studies described here do not provide information concerning the nature of the radioactivity transported once the radiolabeled protein is bound in the liver.

Liver perfusion experiments. Radiolabeled plas$\min (20 \mathrm{pmol})$ was inactivated with PNPGB, incubated for $10 \mathrm{~min}$ at $37^{\circ} \mathrm{C}$ in perfusion buffer, and injected into a prepared liver. The perfused and thoroughly washed liver retained $2.2 \%$ of the administered radioligand. An equivalent quantity of ${ }^{125} \mathrm{I}$-plasmin was perfused into a liver without prior inactivation with PNPGB. Only $2.3 \%$ of the administered radioligand was retained. Incubating the plasmin for $10 \mathrm{~min}$ at $37^{\circ} \mathrm{C}$ with whole blood freshly drawn from a mouse instead of perfusion buffer increased radioactivity retention in the liver to $12.1 \%$. In experiments described above, alkylated plasmin cleared at a slow rate com-

TABLE I

Organ Distribution Studies

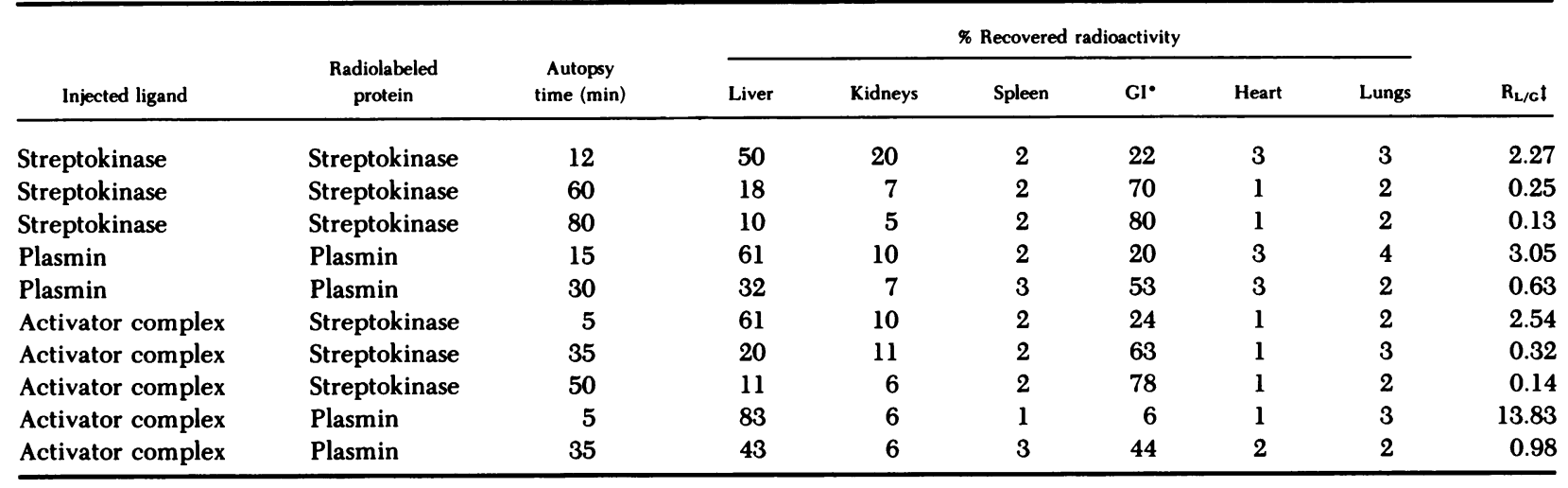

- GI, small and large intestines and stomach.

\$ Ratio of radioactivity in liver compared with gastrointestinal tract. 
parable to that of unmodified plasminogen. The retention of small amounts of PNPGB-plasmin may, therefore, be attributed to background nonspecific binding. Active plasmin failed to bind at levels above background, unless first incubated with whole blood. This result most likely reflects reaction with protease inhibitors and confirms the observation that plasmin cannot be cleared as an isolated protease.

Activator complex containing radiolabeled plasmin was incubated for $10 \mathrm{~min}$ at 23 and $37^{\circ} \mathrm{C}$ in perfusion buffer. Perfused livers retained 1.8 and $2.2 \%$ of these radioligands, respectively. Incubation for $10 \mathrm{~min}$ at $37^{\circ} \mathrm{C}$ in whole blood increased the hepatic binding of the radioligand to $8.0 \%$. These results were confirmed for activator complex containing ${ }^{125} \mathrm{I}$-streptokinase and unlabeled plasmin ( $10.2 \%$ hepatic retention of radioligand following incubation in whole blood as opposed to $2.6 \%$ following incubation in perfusion buffer). Substitution of mouse plasma for whole blood had no significant effect on the hepatic binding of either moiety in activator complex ( $8.3 \%$ retention of plasmin and $9.8 \%$ of retention of streptokinase). These data suggest that activator complex, like plasmin, interacts with plasma proteins mediating hepatic binding.

Role of protease inhibitors in activator complex clearance. Plasma elimination studies have been used to demonstrate that activity is critical for the catabolism of activator complex. Liver perfusion experiments yielded results suggesting that plasma proteins were involved in the pathway. The roles of the plasma protease inhibitors $\alpha_{2} \mathrm{M}$ and $\alpha_{2} \mathrm{PI}$ were, therefore, investigated. Clearance experiments were performed in the presence of competing ligands using the same technique applied to study uncomplexed plasmin clearance (Fig.5 ). The clearance of activator complex (16 pmol) formed with radiolabeled plasminogen was significantly slower when unlabeled $\alpha_{2} \mathrm{M}$-trypsin complex was injected first (Fig. 7). The level of competition observed was dependent upon the molar excess of competing ligand used; however, a 220 -fold molar excess of $\alpha_{2} \mathrm{M}$-trypsin decreased radioligand clearance well outside the limits of experimental error. An equivalent aliquot of plasminogen activator was cleared in the presence of a 550 -fold molar excess of unlabeled $\alpha_{2}$ PIplasmin. Competition was not detectable. $\alpha_{2} M$ and $\alpha_{2}$ PI complexes have been shown to clear through separate noncompetitive pathways. The catabolism of plasmin and activator complex, therefore, depend on reactions with different proteases inhibitors; $\alpha_{2} \mathrm{PI}$ and $\alpha_{2} \mathrm{M}$, respectively.

To further characterize the reaction of plasminogen activator complex with $\alpha_{2} \mathrm{M}$, competition experiments were performed with unlabeled $\alpha_{2} \mathrm{M}$-trypsin and activator complex containing radiolabeled streptokinase. Streptokinase was consistently less susceptible to io-

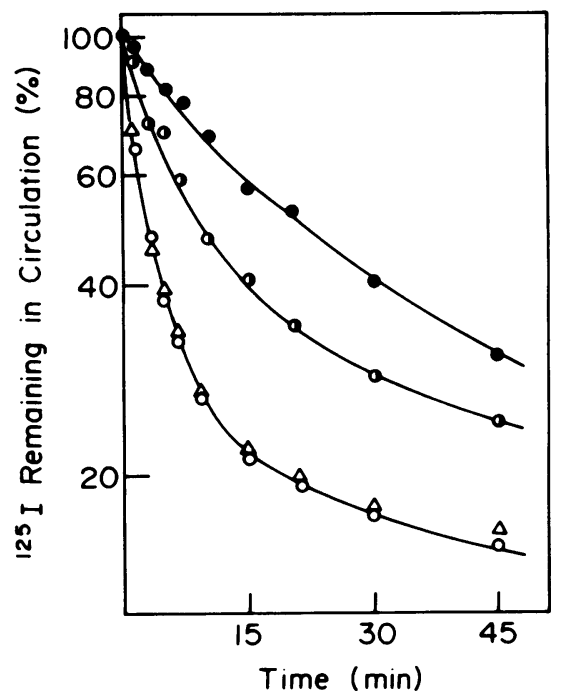

Figure 7 Clearance competition between activator complex containing ${ }^{125} \mathrm{I}$-plasmin and the unlabeled ligands $\alpha_{2} \mathrm{M}$ trypsin and $\alpha_{2}$ PI-plasmin. 16 pmol of activator complex were injected alone $(O)$, in the presence of a 220 -fold molar excess of $\alpha_{2} \mathrm{M}$-trypsin (O), in the presence of a 550 -fold molar excess of $\alpha_{2} \mathrm{M}$-trypsin ( $)$, and in the presence of a 550 -fold molar excess of $\alpha_{2}$ PI-plasmin $(\Delta)$.

dination with lactoperoxidase than was plasminogen. The maximum molar ratio of $\alpha_{2} \mathrm{M}$-trypsin to activator complex studied was, therefore, somewhat lower than that used in the experiments in which the plasminogen was radiolabeled. No competition was observed, however, when 200 pmol of complex were injected in the presence of a 250 -fold molar excess of $\alpha_{2} \mathrm{M}$-trypsin. These experiments suggest that the clearances of streptokinase and plasmin, when injected as a complex, involve separate pathways even though both are eliminated in the liver at accelerated rates compared with the individual proteins. One possible explanation for these data is that activator complex is relatively easily dissociated at $37^{\circ} \mathrm{C}$. This model is, however, inconsistent with experiments that show prolonged clearance of ${ }^{125}$ I-streptokinase in complex inactivated with PTI. In addition, the rapid clearance of the plasmin moiety in activator complex as compared with uncomplexed plasmin (Fig. 2) is inconsistent with a model of simple dissociation. A second explanation consistent with the data is that plasmin is transferred from activator complex to $\alpha_{2} \mathrm{M}$ under conditions where dissociation of the isolated complex does not occur.

Liver perfusion experiments were used to assess the importance of $\alpha_{2} \mathrm{M}$ in the catabolism of the streptokinase moiety in activator complex. Plasminogen activator $(0.2 \mathrm{nmol})$ formed with ${ }^{125} \mathrm{I}$-streptokinase was incubated at $37^{\circ} \mathrm{C}$ for $10 \mathrm{~min}$ with $450 \mu \mathrm{l}$ of perfusion buffer containing $1.7 \mathrm{mg} / \mathrm{ml}$ of human $\alpha_{2} \mathrm{M}$. Hepatic 
retention of the radiolabel was $7.5 \%$, compared to $2.6 \%$ measured when the same incubation was performed in the absence of $\alpha_{2} \mathrm{M}$. Only $2.5 \%$ of the perfused radiolabel was retained after incubation of the activator complex with $\alpha_{2} \mathrm{M}$ at $23^{\circ} \mathrm{C}$. Significant hepatic binding of the streptokinase in activator complex was mediated by an interaction with $\alpha_{2} \mathrm{M}$ at $37^{\circ} \mathrm{C}$, even though the clearance experiments described above suggest that streptokinase is not transferred to $\alpha_{2} \mathrm{M}$ under similar conditions. The reaction or series of reactions responsible for the liver perfusion results was obtained with human protease inhibitor at $37^{\circ} \mathrm{C}$ and not duplicated at $23^{\circ} \mathrm{C}$. In a previous study, $\alpha_{2} \mathrm{M}$ was shown not to interact with streptokinase activator complex (13). The results of this study were, however, obtained at $4^{\circ} \mathrm{C}$, and are therefore not inconsistent with those presented here.

Polyacrylamide gel electrophoresis. Streptokinase, plasmin, and streptokinase activator complex were reacted with $\alpha_{2} \mathrm{M}$ for $40 \mathrm{~min}$ at 23 and $37^{\circ} \mathrm{C}$ using both radiolabeled and nonradiolabeled proteins. Gels containing radiolabeled protein were sectioned as described in Methods. Protein content in electrophoretic bands was determined from measurement of the radioactivity contained within the gel sections with a gamma counter. Control experiments demonstrated no overlap between $\alpha_{2} \mathrm{M}$ bands and the positions of the unreacted radiolabeled proteins studied. The electrophoresis patterns resulting from all of the reactions described below were equivalent when nonradiolabeled proteins were substituted for radiolabeled proteins.

After reaction with proteases $\alpha_{2} \mathrm{M}$ undergoes a conformational change that results in an increase in the electrophoretic mobility of the complexed inhibitor relative to the unreacted protein (43). This increased mobility is clearly demonstrated following reaction with trypsin (Fig. 8). Reaction is apparently complete at 23 and $37^{\circ} \mathrm{C}$. The electrophoretic mobility of $\alpha_{2} \mathrm{M}$ after reaction with plasmin is also increased. The diffuse band obtained may reflect the size of plasmin relative to trypsin and potential heterogeneity in the orientation of plasmin in complex with the inhibitor. The migration of this $\alpha_{2} \mathrm{M}$ complex is indistinguishable following reactions at 23 and $37^{\circ} \mathrm{C}$. The number of moles of radiolabeled plasmin incorporated into complex is essentially equivalent at the two temperatures (1.2 mol plasmin $/ \mathrm{mol}$ of $\alpha_{2} \mathrm{M}$ at $23^{\circ} \mathrm{C}$ and $1.1 \mathrm{~mol}$ plasmin $/ \mathrm{mol} \alpha_{2} \mathrm{M}$ at $37^{\circ} \mathrm{C}$ ).

$\alpha_{2} \mathrm{M}$ was incubated at 23 and $37^{\circ} \mathrm{C}$ with a fivefold molar excess of streptokinase for $40 \mathrm{~min}$. Electrophoresis of these preparations revealed no evidence of significant protein interaction. The mobility of the $\alpha_{2} M$ was unchanged and less than $0.1 \mathrm{~mol}$ of streptokinase were associated with each mol of $\alpha_{2} \mathrm{M}$ in the protease
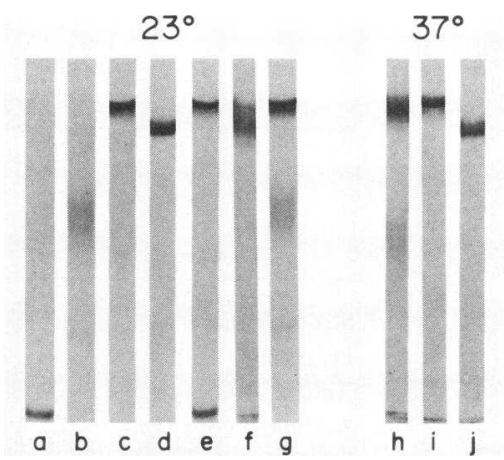

Figure 8 Nondenaturing gel electrophoresis of $\alpha_{2} \mathrm{M}$ complexes. a, streptokinase; b, streptokinase activator complex; c, unreacted $\alpha_{2} M ; d, \alpha_{2} M$ in the "fast" conformation following reaction with trypsin; $e, \alpha_{2} M$ incubated with a fivefold molar excess of streptokinase; $f, \alpha_{2} M$-plasmin complex; $g$, $\alpha_{2} \mathrm{M}$ incubated with activator complex. Reaction for lanes a-g proceeded for $40 \mathrm{~min}$ at $23^{\circ} \mathrm{C}$ before electrophoresis. Equivalent incubations were performed at $37^{\circ} \mathrm{C}$ yielding identical results in all cases except for the reaction of $\alpha_{2} M$ with activator complex (lane h). $i$ and $j$, native $\alpha_{2} \mathrm{M}$ and $\alpha_{2} \mathrm{M}$-trypsin electrophoresed after incubations at $37^{\circ} \mathrm{C}$ are included for comparison.

inhibitor electrophoretic band (Table II). These findings are in agreement with a previous study performed at ambient temperature (13).

Activator complex was prepared in the presence of a twofold molar excess of streptokinase. Incubation of $\alpha_{2} \mathrm{M}$ with a fourfold molar excess of activator complex resulted in a temperature dependent reaction similar to that detected in the liver perfusion studies. The electrophoretic migration of the $\alpha_{2} \mathrm{M}$ was significantly altered after incubation at $37^{\circ} \mathrm{C}$. At $23^{\circ} \mathrm{C}$ the mobility was, at best, marginally altered compared with unreacted $\alpha_{2} \mathrm{M}$. This result was confirmed for activator complex formed with radiolabeled streptokinase and complex formed with radiolabeled plasminogen. Only the radiolabeled plasmin became significantly associated with the $\alpha_{2} M$ (Table II). If streptokinase participated in the formation of a ternary complex, the association was too weak to be maintained during the course of the electrophoresis experiments. The association of $0.8 \mathrm{~mol}$ of ${ }^{125} \mathrm{I}$-plasmin with $1.0 \mathrm{~mol}$ of $\alpha_{2} \mathrm{M}$ after incubation at $37^{\circ} \mathrm{C}$ represented a fourfold increase over the association measured at $23^{\circ} \mathrm{C}$. These data are in good agreement with the in vivo studies, which suggest that activator complex reacts with $\alpha_{2} \mathrm{M}$ resulting in the transfer of plasmin to the protease inhibitor.

Complex formation between $\alpha_{2} \mathrm{M}$ and protease is initiated by proteolytic attack resulting in the cleavage of the $\alpha_{2} \mathrm{M}$ subunit $(180,000 \mathrm{~mol} \mathrm{wt})$ into two polypeptide chains that are nearly equivalent in size (44). $\mathrm{NaDODSO}_{4}$ gel electrophoresis of samples reduced 
TABLE II

Association of Radioligands with $\alpha_{2}$-Macroglobulin after

Nondenaturing Gel Electrophoresis

\begin{tabular}{llcc}
\hline & & \multicolumn{2}{c}{ Association (mol of ligand $/ \mathrm{mol} \alpha_{2} \mathrm{M}$ ) } \\
\cline { 3 - 4 } \multicolumn{1}{c}{ Ligand } & \multicolumn{1}{c}{$\begin{array}{c}\text { Radiolabeled } \\
\text { protein }\end{array}$} & $\begin{array}{c}40 \text { min incubation } \\
\text { at } 23^{\circ} \mathrm{C}\end{array}$ & $\begin{array}{c}40 \text { min incubation } \\
\text { at } 37^{\circ} \mathrm{C}\end{array}$ \\
\hline Streptokinase & Streptokinase & 0.04 & 0.02 \\
Plasmin & Plasmin & 1.2 & 1.1 \\
Activator complex & Streptokinase & 0.02 & 0.02 \\
Activator complex & Plasmin & 0.2 & 0.8 \\
\hline
\end{tabular}

with dithiothreitol clearly shows this reaction following incubation of $\alpha_{2} \mathrm{M}$ with a threefold molar excess of trypsin (Fig. 9). A second band of faster mobility than the $\alpha_{2} \mathrm{M}$ subunit is present in the lane in which unreacted $\alpha_{2} \mathrm{M}$ is electrophoresed. This and another band that is not apparent in the figure result from incubation of $\alpha_{2} \mathrm{M}$ at temperatures of $37^{\circ} \mathrm{C}$ or above in denaturing solution (45). Incubation of $\alpha_{2} \mathrm{M}$ with a 12-fold molar excess of streptokinase for $40 \mathrm{~min}$ failed to result in subunit cleavage. This result was duplicated at both 23 and $37^{\circ} \mathrm{C}$. Subunit cleavage is apparent, although incomplete, following reaction of $\alpha_{2} \mathrm{M}$ and a threefold molar excess of plasmin for $\mathbf{4 0}$ min. Intact subunit remained following incubations for longer time periods and at higher temperatures $\left(37^{\circ} \mathrm{C}\right)$. This result may reflect the lower binding ratio of plasmin to $\alpha_{2} \mathrm{M}$ as compared to trypsin (43). The additional

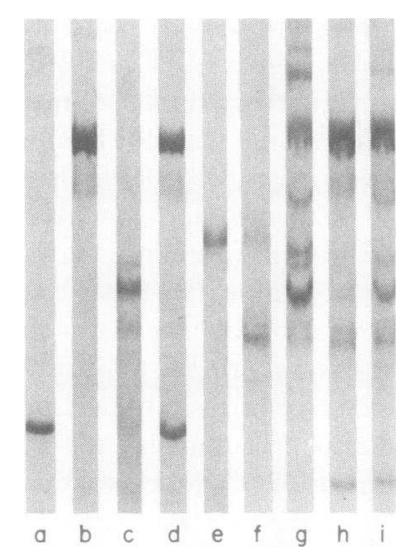

Figure 9 NaDODSO ${ }_{4}$ gel electrophoresis of reduced samples (5\% slab). a, streptokinase; b, unreacted $\alpha_{2} \mathrm{M} ; \mathrm{c}, \alpha_{2} \mathrm{M}$ trypsin complex; $\mathrm{d}, \alpha_{2} \mathrm{M}$ incubated with streptokinase; $\mathrm{e}$, plasminogen; $f$, plasminogen activated to form plasmin for $40 \mathrm{~min}$ with catalytic quantities of urokinase as described in Methods. $g$, plasmin preparation from lane $f$ incubted with $\alpha_{2} M$ for an additional $40 \mathrm{~min}$. $\mathrm{h}$, activator complex incubated with $\alpha_{2} \mathrm{M}$ at $23^{\circ} \mathrm{C}$; i, activator complex incubated with $\alpha_{2} \mathrm{M}$ at $37^{\circ} \mathrm{C}$. Incubations of $\alpha_{2} \mathrm{M}$ with streptokinase, trypsin, and activator complex proceeded for $40 \mathrm{~min}$. high molecular weight bands present in this lane most likely represent covalent adducts of either the heavy or light chain of plasmin to one or more $\alpha_{2} \mathrm{M}$ subunits $(40,46)$.

Activator complex was prepared with a twofold molar excess of streptokinase and then incubated with $\alpha_{2} \mathrm{M}$ (activator complex: $\alpha_{2} \mathrm{M}$ incubation molar ratio of $4: 1$ ). After $40 \mathrm{~min}$ of incubation at $23^{\circ} \mathrm{C}$ minimal $\alpha_{2} \mathrm{M}$ subunit cleavage was detected. Elevation of the incubation temperature to $37^{\circ} \mathrm{C}$ once again produced evidence of significant reaction. These in vitro studies confirm that at physiological temperature human $\alpha_{2} \mathrm{M}$ is capable of reacting with streptokinase activator complex in a manner equivalent to that detected for mouse $\alpha_{2} \mathrm{M}$ with in vivo experiments.

\section{DISCUSSION}

The first aim of this investigation was to study the plasma elimination of uncomplexed streptokinase. Previous studies have included organ distribution experiments in mice and clearance studies in dogs (8-10). These two species have plasminogens with different affinities for streptokinase $(11,47)$. It is conceivable, therefore, that different ligands were actually studied by the two experimental techniques. In the present study radiolabeled streptokinase was sequestered in the liver following intravenous injection into mice. Clearance in mice was more rapid than in dogs (8-10) despite the inability of the radioligand to form activator complex in the rodent circulation. Plasma elimination of streptokinase was dominated by one major phase and no evidence was obtained implicating plasma protein interaction in the clearance pathway.

The organ primarily responsible for the clearance of plasmin was the liver. Maintenance of an uninhibited active site was critical for the clearance of this ligand. Hepatic binding of ${ }^{125} \mathrm{I}$-plasmin occurred only after the protease was incubated with blood. These experiments suggest that reaction with protease inhibitors is the only significant mechanism mediating the plasma elimination of plasmin. 
$\alpha_{2}$ PI-plasmin, prepared in vitro, cleared from the circulation of mice, although at a somewhat slower rate than some of the other protease inhibitor complexes $(14,15)$. Large molar excesses of unlabeled $\alpha_{2}$ PI-plasmin significantly retarded the clearance of the radiolabeled complex. Competition indicates that the pathway for catabolism of $\alpha_{2}$ PI-plasmin is specific and saturable. Clearance of $\alpha_{2}$ PI-plasmin did not involve the $\alpha_{2} \mathrm{M}$ receptor system. This information permitted the use of clearance competition experiments to demonstrate that plasmin is bound primarily to $\alpha_{2} \mathrm{PI}$ and not to $\alpha_{2} \mathrm{M}$ when injected into the circulation.

$\alpha_{2} \mathrm{M}$-plasmin was cleared by the same receptor system that binds $\alpha_{2} \mathrm{M}$-trypsin and $\alpha_{2} \mathrm{M}$-methylamine (15). This receptor recognizes conformational change in the $\alpha_{2} \mathrm{M}$ macromolecule and is grossly uninfluenced by the bound ligand. The slightly prolonged clearance rate of $\alpha_{2} \mathrm{M}$-plasmin relative to $\alpha_{2} \mathrm{M}$-trypsin and $\alpha_{2} \mathrm{M}$ methylamine may reflect some minor steric hindrance to receptor binding caused by the relatively large plasmin molecule.

The strong affinity of streptokinase for human plasminogen was a major consideration in the decision to study reactions that might take place in the circulation that lead to the neutralization of the activator complex. The clearance of streptokinase following incubation with human plasma was equivalent to the clearance of activator complex formed with purified plasminogen. It is therefore likely that the fraction of free streptokinase circulating in human plasma after intravenous infusion is low.

Plasminogen activator complex cleared from the circulation extremely quickly compared with uncomplexed plasmin and streptokinase. First order clearance kinetics were not demonstrated by activator complex, suggesting some heterogeneity in the elimination pathway. Nevertheless, the percentage of rapidly clearing radioligand consistently represented the majority of the injected preparation.

The clearance of activator complex was studied in the presence of large molar excesses of unlabeled $\alpha_{2} \mathrm{PI}$ plasmin and $\alpha_{2} \mathrm{M}$-trypsin. The competing ligands were saturated complexes and they did not contribute to the protease inhibitory capacity of the plasma. $\alpha_{2} \mathrm{M}$-trypsin significantly retarded the clearance of the plasmin in activator complex, whereas $\alpha_{2}$ PI-plasmin did not, in contrast to the result observed for uncomplexed plasmin. No competition was detected when radiolabeled streptokinase was incorporated into activator complex and studied in the presence of competing $\alpha_{2} \mathrm{M}$-trypsin. These data are consistent with a model in which plasmin is transferred from streptokinase to $\alpha_{2} \mathrm{M}$. Competing $\alpha_{2} \mathrm{M}$-trypsin would not be expected to have an effect on the reaction of activator complex with circulating mouse $\alpha_{2} \mathrm{M}$. Once reaction has oc- curred, competing ligand would prolong the clearance of the plasmin that is bound to $\alpha_{2} \mathrm{M}$, but have no effect on the streptokinase that is not associated with the protease inhibitor.

Two mechanisms are recognized whereby plasmin may be transferred from activator complex to $\alpha_{2} \mathrm{M}$. Transfer may result from the establishment of equilibrium between independent reactions (the dissociation of activator complex and reaction between $\alpha_{2} \mathrm{M}$ and plasmin). Alternatively, transfer may involve activator complex attack on an $\alpha_{2} \mathrm{M}$ "bait region," resulting in the trapping of the plasmin by the protease inhibitor and dissociation of the streptokinase. Although these two mechanisms are not mutually exclusive, the second is thought to predominate in vivo for the following reasons. (a) The independent reactions mechanism fails to explain the accelerated clearance of ${ }^{125} \mathrm{I}$-plasmin in activator complex. (b) The clearance rate of the streptokinase in activator complex is decreased by inhibition of the active site on the plasmin moiety with either PNPGB or PTI. It is unlikely that this result reflects a change in the association properties of the complex since PTI does not alter the affinity of streptokinase for plasmin (4), even though PNPGB may (48). Circulating inactive plasmin would not be expected to prolong the clearance rate of streptokinase since excess human plasminogen did not have this effect when it was injected along with the activator complex formed in vitro with human plasma. There is therefore, no apparent explanation for the clearance of ${ }^{125} \mathrm{I}$-streptokinase in PTI inactivated complex that is consistent with independent dissociation. $(c)$ It is difficult to explain the predominant role of $\alpha_{2} \mathrm{M}$ in the binding of plasmin with the first model of independent reactions. Streptokinase activator complex and uncomplexed plasmin are known to have different substrate specificities (41). Activator complex is less reactive with $\alpha_{2}$ PI than is free plasmin (3). The reaction of circulating plasmin and streptokinase activator complex with different protease inhibitors is most simply explained as different enzymes attacking preferred substrates. It is concluded that the mechanism of plasmin transfer most consistent with all of the data accumulated in this investigation is the second, which implicates $\alpha_{2} \mathrm{M}$ as playing an active role in the dissociation of the activator complex. When the active site of the activator complex is inhibited, the clearance of the streptokinase in the complex become dependent on passive dissociation, a significantly slower reaction (Fig. 6). Passively dissociated streptokinase still may be cleared in the liver while alkylated plasmin is not, explaining the discrepancy in the clearance rates of the two moieties in PNPGB-treated plasmin.

These studies raise two additional questions, both of which are speculative at present. The first involves 
how $\alpha_{2} \mathrm{M}^{125} \mathrm{I}$-plasmin formed in vivo from reaction with activator complex clears more rapidly than $\alpha_{2} \mathrm{M}$ plasmin prepared in vitro and administered directly. If one accepts the "plasmin transfer" model, it may be postulated that transfer results in an orientation of the plasmin in complex with $\alpha_{2} \mathrm{M}$, which is different from that found after the binding of free plasmin by $\alpha_{2} M$. Macrophage binding studies are presently underway to test this hypothesis. Finally, why does streptokinase demonstrate accelerated clearance following dissociation from activator complex? Fragmentation of streptokinase is known to occur rapidly when in complex with plasmin(ogen), although no fragments are lost (49). In this investigation, a hepatic clearance pathway for streptokinase that appeared not to involve plasminogen was detected. Further studies will be required to determine whether dissociated streptokinase utilizes the same pathway.

\section{REFERENCES}

1. DeRenzo, E. C., P. K. Sitteri, B. L. Hutchings, and P. H. Bell. 1967. Preparation and certain properties of highly purified streptokinase. J. Biol. Chem. 242: 533542.

2. McClintock, D. K. and P. H. Bell. 1971. The mechanism of activation of human plasminogen by streptokinase. Biochem. Biophys. Res. Commun. 3: 694-702.

3. Cedeholm-Williams, S. A., F. DeCock, H. R. Lijnen, and D. Collen. 1979. Kinetics of the reaction between streptokinase, plasmin and $\alpha_{2}$-antiplasmin. Eur. J. Biochem. 100: 125-132.

4. Gonzalez-Gronow, M., G. E. Siefring Jr., and F. J. Castellino. 1978. Mechanism of activation of human plasminogen by the activator complex, streptokinase-plasmin. J. Biol. Chem. 253: 1090-1094.

5. Tillett, W. S., and S. Sherry. 1949. The effect in patients of streptococcal fibrinolysin (streptokinase) and streptococcal desoxyribonuclease on fibrinous purulent and sanguinous pleural exudations. J. Clin. Invest. 28: 173190.

6. Johnson, A. J., and W. R. McCarty. 1959. The lysis of artifically induced intra-vascular clots in man by intravenous infusions of streptokinase. J. Clin. Invest. 38: 1627-1643.

7. Fletcher, A. P., N. Alkjaersig, F. E. Smyrniotis, and S. Sherry. 1958. The treatment of patient suffering from early myocardial infarction with massive prolonged streptokinase therapy. Trans. Assoc. Am. Physicians. 71: 287-296.

8. Som, P., B. A. Rhodes, and W. R. Bell. 1975. Radiolabeled streptokinase and urokinase and their comparative biodistribution. Thromb. Res. 6: 247-253.

9. Coates, G., S. J. DeNardo, and F. A. Troy. 1975. Pharmacokinetics of radioiodinated streptokinase. J. Nucl. Med. 16: 136-142.

10. Back, N., J. L. Ambrus, and I. B. Mink. 1964. Distribution and fate of $\mathrm{I}^{131}$-labeled components of the fibrinolysin system. Circ. Res. 9: 1208-1216.

11. Wulf, R. J., and E. T. Mertz. 1969. Studies on plasminogen. VIII. Species specificity of streptokinase. Can. J. Biochem. 47: 927-931.

12. Wiman, B. 1980 . On the reaction or plasmin or plasmin- streptokinase complex with aprotinin or $\alpha_{2}$-antiplasmin Thromb. Res. 17: 143-152.

13. Steinbuch, M., A. Freiss, J. Drouet, and P. Amouch. 1975. Absence of interaction between streptokinase/ plasmin(ogen) complexes and $\alpha_{2}$-macroglobulin. Thromb. Diath. Haemorh. 34: 922-923.

14. Shifman, M. A., and S. V. Pizzo. 1982. The in vivo metabolism of antithrombin III and antithrombin III complexes. J. Biol. Chem. 257: 3243-3248.

15. Imber, M. J., and S. V. Pizzo. 1981. Clearance and binding of two electrophoretic "fast" forms of human $\alpha_{2}$ macroglobulin. J. Biol. Chem. 256: 8134-8139.

16. Fuchs, H. E., M. A. Shifman, and S. V. Pizzo. 1982. Studies on the in vivo metabolism of $\alpha_{1}$-proteinase inhibitor and its complexes with trypsin. Biochim. Biophys. Acta. 716: 151-157.

17. Mullertz, S., and I. Clemmensen. 1976. The primary inhibitor of plasmin in human plasma. Biochem. J. 159: 545-553.

18. Wiman, B., and D. Collen. 1978. On the kinetics of the reactions between human antiplasmin and plasmin. Eur. J. Biochem. 84: 573-578.

19. Harpel, P. C. 1977. Plasmin inhibitor interactions. The effectiveness of $\alpha_{2}$-plasmin inhibitor in the presence of $\alpha_{2}$-macroglobulin. J. Exp. Med. 146: 1033-1040.

20. Deutsch, D. G., and E. T. Mertz. 1970. Plasminogen: purification from human plasma by affinity chromatography. Science (Wash. DC). 170: 1095-1096.

21. Brockway, W. J., and F. J. Castellino. 1972. Measurement of the binding of antifibrinolytic amino acids to various plasminogens. Arch. Biochem. Biophys. 151: 194-199.

22. Einarsson, M., B. Skoog, B. Forsberg, and R. Einarsson 1979. Characterization of highly purified native streptokinase and altered streptokinase after alkaline treatment. Biochim. Biophys. Acta. 568: 19-29.

23. Violand, B. N., and F. J. Castellino. 1976. Mechanism of the urokinase-catalyzed activation of human plasminogen. J. Biol. Chem. 251: 3906-3912.

24. Chase, T., and E. Shaw. 1967. p-Nitrophenyl-p'-guanidinobenzoate $\mathrm{HCl}$ : a new active site titrant for trypsin. Biochem. Biophys. Res. Commun. 29: 508-514.

25. Iio, M., H. N. Wagner Jr., U. Scheffel, and B. Jabbour. 1963. Studies of the reticuloendothelial system (RES). I. Measurement of the phagocytic capacity of the RES in man and dog. J. Clin. Invest. 42: 417-426.

26. Sjoholm, I., B. Wiman, and P. Wallen. 1973. Studies on the conformational changes of plasminogen induced during activation to plasmin and by 6 -aminohexanoic acid. Eur. J. Biochem. 39: 471-479.

27. Hall, P. K., and R. C. Roberts. 1978. Physical and chemical properties of human plasma $\alpha_{2}$-macroglobulin. Biochem. J. 171: 27-38.

28. Moroi, M., and N. Aoki. 1976. Isolation and characterization of $\alpha_{2}$-plasmin inhibitor from human plasma. $J$. Biol. Chem. 251: 5956-5965.

29. David, G. S., and R. A. Reisfeld. 1974. Protein iodination with solid state lactoperoxidase. Biochemistry. 13: 10141021.

30. Nelles, L. P., P. K. Hall, and R. C. Roberts. 1980. Human $\alpha_{2}$-macroglobulin studies on the electrophoretic heterogeneity. Biochim. Biophys. Acta. 623: 46-56.

31. Wyckoff, M., D. Rodbard, and A. Chrambach. 1977. Polyacrylamide gel electrophoresis in sodium dodecyl sulfate-containing buffers using multiphasic buffer systems: properties of the stack, valid $R_{f}$ measurement, and optimized procedure. Anal. Biochem. 78: 459-482. 
32. Harpel, P. C. 1981. $\alpha_{2}$-Plasmin inhibitor and $\alpha_{2}$-macroglobulin-plasmin complexes in plasma. J. Clin. Invest. 68: 46-55.

33. Lollar, P., and W. G. Owen. 1980. Clearance of thrombin from circulation in rabbits by high-affinity binding sites on endothelium. J. Clin. Invest. 66: 1222-1230.

34. Wiman, B., and D. Collen. 1979. On the mechanism of the reaction between human $\alpha_{2}$-antiplasmin and plasmin. J. Biol. Chem. 254: 9291-9297.

35. Barrett, A. J., and P. M. Starkey. 1973. The interaction of $\alpha_{2}$-macroglobulin with proteinases. Biochem. J. 133: 709-724.

36. Ohlsson, K. 1971. Elimination of ${ }^{125} \mathrm{I}$ trypsin $\alpha_{2}$-macroglobulin complexes from blood by reticuloendothelial cells in dog. Acta Physiol. Scand. 81: 269-272.

37. Kaplan, J., and M. L. Nielson. 1979. Analysis of macrophage surface receptors. J. Biol. Chem. 254: 73237328.

38. Aoki, N., M. Moroi, and K. Tachiya. 1978. Effects of $\alpha_{2}$-plasmin inhibitor on fibrin clot lysis. Its comparison with $\alpha_{2}$-macroglobulin. Thromb. Haemostasis. 39: 2231.

39. Gonias, S. L., and S. V. Pizzo. 1981. Altered clearance of human $\alpha_{2}$-macroglobulin complexes following reaction with cis-dichlorodiamineplatinum (II). Biochim. Biophys. Acta. 678: 268-274.

40. Sottrup-Jensen, L., T. E. Petersen, and S. Magnusson. 1981. Mechanism of proteinase complex formation with $\alpha_{2}$-macroglobulin. FEBS (Fed. Eur. Biochem. Soc.) Lett. 128: $127-132$.
41. Bajaj, S. P., and F. J. Castellino. 1977. Activation of plasminogen by equimolar levels of streptokinase. $J$. Biol. Chem. 252: 492-498.

42. Renston, R. H., A. L. Jones, W. D. Christiansen, and G. T. Hradek. 1980. Evidence for a vesicular transport mechanism in hepatocytes for biliary secretion of immunoglobulin A. Science (Wash. DC) 208: 1276-1278.

43. Barrett, A. J., M. A. Brown, and C. A. Sayers. 1979. The electrophoretically "slow" and "fast" forms of the $\alpha_{2}$ macroglobulin molecule. Biochem. J. 181: 401-418.

44. Harpel, P. C. 1973. Studies on human plasma $\alpha_{2}$ macropglobulin enzyme interactions. Evidence for proteolytic modification of the subunit chain structure. $J$. Exp. Med. 138: 508-521.

45. Harpel, P. C., M. B. Hayes, and T. E. Hugli. 1979. Heat induced fragmentation of human $\alpha_{2}$-macroglobulin. $J$. Biol. Chem. 254: 8669-8678.

46. Salvesen, G. S., and A. J. Barrett. 1980. Covalent binding of proteinases in their reaction with $\alpha_{2}$-macroglobulin. Biochem. J. 187: 695-701.

47. Summaria, L., L. Arzadon, P. Bernabe, and K. C. Robbins. 1974. The interaction of streptokinase with human, cat, dog and rabbit plasminogens. J. Biol. Chem. 249: 4760-4769.

48. Reddy, K. N., and G. Markus. 1972. Mechanism of activation of human plasminogen by streptokinase. J. Biol. Chem. 247: 1683-1691.

49. Summaria, L., K. C. Robbins, and G. H. Barlow. 1971. Dissociation of the equimolar human plasmin-streptokinase complex. J. Biol. Chem. 246: 2136-2142. 